\title{
INHIBITORY CONTROL AND PEER PASSENGERS PREDICT RISKY DRIVING IN YOUNG NOVICE DRIVERS - A SIMULATOR STUDY
}

\author{
Ellen M.M. Jongen ${ }^{1}$, Kris Brijs ${ }^{1,2}$, Tom Brijs ${ }^{1}$ \& Geert Wets ${ }^{1}$ \\ ${ }^{1}$ Transportation Research Institute (IMOB), Hasselt University, Diepenbeek, Belgium \\ ${ }^{2}$ XIOS University College, Department of Construction Engineering, Diepenbeek, Belgium \\ Email: ellen.jongen@uhasselt.be
}

\begin{abstract}
Summary: This driving simulator study aimed to investigate (1) effects of peer passengers on a variety of risky driving measures, and (2) moderating effects of inhibitory control on these peer passenger effects. Two age groups $(n=30,17-18$ year-olds; $n=20,21-24$ year-olds) participated. Each participant completed two $28 \mathrm{~km}$ test-drives in a medium-fidelity driving simulator. In the first drive, participants were asked to drive as they normally do. In the second drive, participants again were asked to drive as they normally do, now in the presence of a peer passenger. Measures of risky driving were: standard deviation of lateral lane position (SDLP), collisions with road hazards, speeding, and red light running. The results showed: (1) that peer presence can have negative ('risk increasing') but also positive ('protective') effects on driving performance, depending on the specific driving measure: whereas red light running increased, the number of collisions and SDLP decreased with peer passengers; (2) a moderating effect of inhibitory control on the peer passenger effect of speeding as (a) in a sub-group with low inhibitory control an increase in speeding occurred with peers, while (b) in a sub-group with high inhibitory control there was no effect of peers on speeding. This suggests that those with higher inhibitory control are more successful in resisting peer pressure.
\end{abstract}

\section{INTRODUCTION}

Driving with peer passengers increases young novice drivers' crash risk (Williams et al., 2007). Two potential explanatory factors for this elevated crash risk can be derived from the field of developmental cognitive neuroscience (Yurgelun-Todd, 2007): suboptimal cognitive control and increased reward sensitivity. Cognitive control is an umbrella term that refers to a collection of cognitive functions including inhibitory control, working memory, mental flexibility and planning (Huizinga, Dolan, \& van der Molen, 2006). It is important for the regulation of complex behavior, including performance of appropriate and inhibition of inappropriate actions. In adolescence, cognitive control does not function in an optimal way, and it still advances until the age of about 30 (Crone \& Dahl, 2012). In addition to suboptimal cognitive control, sensitivity of the affective brain system involved in the evaluation of rewards increases, resulting in increased reward sensitivity at the start of adolescence. Especially in rewarding contexts adolescents may therefore be prone to risk taking behavior, when their increased reward-seeking impulses are not appropriately inhibited by cognitive control (Figner et al., 2009). In addition to physiological (drugs) and financial rewards, an important source of rewards during adolescence consists of peers, their opinions and social evaluations.

The differential involvement of cognitive control and reward sensitivity in the effect of peer passengers on risky driving for adolescent versus adult drivers has been studied in a driving 
video game (Gardner \& Steinberg, 2005; Chein et al., 2010). As hypothesized a stronger increase in red light running was shown in adolescents than adults when participants played the game in the presence of peers. Chein et al. showed that adolescents selectively demonstrated greater reward-related brain activity when peers were present. Furthermore, brain regions associated with cognitive control were recruited less by adolescents than adults, independent of peer presence. It was therefore concluded that peer presence increases adolescent risk taking by heightening sensitivity to the potential reward value of risky decisions. These two studies are highly valuable. At the same time, some methodological aspects could be improved as the video game was played from a third-person, non-participating, side-view perspective, the investigation of risky driving was limited to red light running, and different functions of cognitive control (e.g., inhibitory control) were not measured (Gardner \& Steinberg) or discriminated (Chein et al.). Measurement of separate cognitive functions might be of interest as we recently showed that both the strength and direction of the relation between different cognitive functions and driving differs (Ross, Jongen, Brijs, Ruiter, Brijs, \& Wets, submitted). In addition measurement of separate cognitive functions would be of interest because individual differences in cognitive control might moderate the effect of peer passengers on risky driving by reducing the impact of increased reward sensitivity (Crone \& Dahl, 2012).

The present study aimed to investigate developmental differences in the effect of peer passengers on driving while taking into account the factors mentioned above: (1) four different measures of risky driving (i.e., SDLP, road hazards, speeding, red light running) were studied (2) in a medium fidelity driving simulator, (3) with separate measurement of one specific function of cognitive control (i.e., inhibitory control) to investigate possible moderating effects of cognitive control. Similar to the previous studies different age groups were compared.

\section{METHOD}

\section{Participants}

Fifty young drivers were recruited using the inclusion criteria: (1) age between 17-18 years or 21-24 years, (2) a full or provisional driving license, (3) no more than two years driving experience at the time of testing. All participants gave informed consent, had normal/correctedto-normal vision, and none suffered from simulator sickness. Two age groups ( $\mathrm{n}=30$, mean age 17.8 years, 18 male drivers; $n=20$, mean age 21.5 years, 13 male drivers) were matched in terms of driver gender ratios (60\% versus 65\% male drivers), and driver gender was included in the design as a possible moderating factor as especially male drivers have an increased accident risk (Ouimet et al., 2010). Self-reported driving experience was higher for 22-24 year-olds (2883 $\mathrm{km} /$ year) than $17-18$ year-olds $(1627 \mathrm{~km} /$ year $) ; \mathrm{F}(1,48)=4.2, \mathrm{p}=.047)$, and was included in the analyses as a covariate. Every driver was asked to invite a peer passenger of any gender. Mean age/gender of the peer passengers were 17.6 years/16 male versus 22.3 years/12 male, for the 1718 year-old group and 21-24 year-old group, respectively. Since there was not an equal distribution of male and female passengers across male and female drivers of the two age groups, and given the current sample size, passenger gender was not included as a factor in the analyses. 


\section{Driving simulator}

The experiment was conducted on a fixed-based medium-fidelity driving simulator (STISIM M400; Systems Technology Incorporated) with a force-feedback steering wheel, brake pedal, and accelerator and a large $180^{\circ}$ field of view seamless curved screen, with rear view and sideview mirror images. The projection screen offered a resolution of $1024 \times 768$ pixels and data were collected at a $60 \mathrm{~Hz}$ frame rate.

\section{Stop signal paradigm}

As a standard laboratory measure of inhibitory control, the stop signal paradigm was used ( Verbruggen \& Logan, 2008). A two-choice reaction time task required participants to press a button (left or right) in response to a stimulus (an ' $\mathrm{X}$ ' or an 'O') presented centrally on screen. In each trial after $1000 \mathrm{~ms}$ a fixation cross was presented for $500 \mathrm{~ms}$. Then the stimuli were presented for $1000 \mathrm{~ms}$ and required a response between 150-1000 ms after onset. On a randomly selected 25\% of the trials, an auditory stimulus $(1000 \mathrm{~Hz}, 70 \mathrm{~dB}, 100 \mathrm{~ms})$ was presented in addition to the visual primary-task stimulus. Presentation of this tone designated that the subject was to refrain from responding to the stimulus on that trial. Initially, the time interval between the stimulus and the stop-signal was set 50 ms below participants' individual speed level. Subsequently the interval varied dynamically according to a staircase tracking algorithm, to converge on a stop-signal delay at which the probability of stopping is 50\%. Stop-signal delay was increased by $50 \mathrm{~ms}$ if the response was withheld and decreased by $50 \mathrm{~ms}$ when it was not. For a full description of practice and experimental sessions, see Jongen et al. (2011).

\section{Scenarios}

The simulated driving task consisted of two warm-up sessions and two experimental sessions. In the experimental sessions a 28km daylight driving scenario was presented on a two-lane road with bidirectional traffic, including both inner (50km/hour)- and outer (90km/hour)-city sections. Twelve road hazards (e.g., a pedestrian crossing the road) were calibrated such that crashes could be avoided by braking (when driving at speed limit) or steering around the obstacle. Apart from road hazards, other vehicles were presented on the roadway but required no passing or braking on the part of the driver. In the scenario, participants had to drive through 18 intersections equipped with traffic lights (10 red; 4 green; 4 yellow, in randomized order).

\section{Peer passengers}

For the first session ride, participants were instructed to drive as they would normally do. For the second session ride, participants drove with a peer that sat in a chair to the right of them. Driver and peer were asked to drive, behave and interact as they would normally do. The experimenter left the room during the two experimental rides. In line with Fillmore et al (2008) and Jongen et al. (2011), session order was not balanced, and the ride without peers was presented first.

\section{Data collection and analysis}

Inhibitory control. The stop signal reaction time (SSRT) was used as a measure of inhibitory control with shorter SSRT indicating higher inhibitory control. 
Risky driving behavior. Measures of risky driving included collisions with road hazards, speeding (percentage of total distance above the speed limit), red light running (number of times) and standard deviation of lateral lane position (SDLP). In the computation of SDLP, segments associated with lane changes were excluded. For each of the dependent measures a separate repeated measures ANOVA was conducted with within-subjects factor peers (2: no, yes), between-subjects factors age (2: 17-18 year-olds, 22-24 year-olds) and driver gender (2: male, female), and continuous predictor variables (covariates) inhibitory control (i.e., SSRT) and driving experience.

\section{RESULTS}

\section{Risk Behavior}

Results are presented in Table 1 and Table 2.

Road hazards. The number of collisions with road hazards was significantly lower in the ride with peers.

SDLP. SDLP was significantly lower in the ride with peers.

Speeding. The occurrence of speeding was significantly higher in 17-18 year-olds (20.3\%) than 21-24 year-olds (12.0\%), and in male drivers (19.9\%) than female drivers (12.4\%). Importantly, there was a significant interaction effect of inhibitory control and peers. To further investigate this effect, a median split was applied the measure of inhibitory control (i.e., SSRT). Separate analyses for the low and high inhibitory control group showed that speeding increased in the ride with peers in the low inhibitory control group $(12.4 \%$ versus $16.8 \% ; \mathrm{F}(1,20)=17.0, \mathrm{p}=.001)$, whereas there was no difference in speeding between rides in the high inhibitory control group $(19.3 \%$ versus $16.3 \% ; \mathrm{F}(1,20)=1.7, \mathrm{p}=.20)$. In addition, there was no significant difference between the low and high inhibitory group without peers or with peers.

Red light running. Red light running was significantly higher in the ride with peers.

Table 1. Means (m) and standard errors (SE) of risky driving behavior by age group and peer condition

\begin{tabular}{|c|c|c|c|c|}
\hline & \multicolumn{2}{|c|}{ No peers } & \multicolumn{2}{|c|}{ Peers } \\
\hline & $\begin{array}{l}\text { 17-18 } \\
\text { yr }\end{array}$ & $\begin{array}{l}21-24 \\
\text { yr }\end{array}$ & 17-18 yr & $21-24$ yr \\
\hline \multirow{2}{*}{$\begin{array}{c}\text { SDLP } \\
\text { (meters) }\end{array}$} & $\mathrm{m}=.256$ & $\mathrm{~m}=.257$ & $\mathrm{~m}=.240$ & $\mathrm{~m}=.237$ \\
\hline & $\mathrm{SE}=.010$ & $\mathrm{SE}=.012$ & $\mathrm{SE}=.012$ & $\mathrm{SE}=.015$ \\
\hline \multirow{2}{*}{$\begin{array}{c}\text { Speeding } \\
\text { (\% of distance) }\end{array}$} & $\mathrm{m}=18.7$ & $m=12.7$ & $\mathrm{~m}=21.8$ & $\mathrm{~m}=11.4$ \\
\hline & $\mathrm{SE}=2.40$ & $\mathrm{SE}=3.0$ & $\mathrm{SE}=2.41$ & $\mathrm{SE}=3.0$ \\
\hline \multirow{2}{*}{$\begin{array}{l}\text { Red light } \\
\text { running } \\
\text { (\# of times) }\end{array}$} & $\mathrm{m}=.07$ & $\mathrm{~m}=.01$ & $\mathrm{~m}=.16$ & $\mathrm{~m}=.22$ \\
\hline & $\mathrm{SE}=.04$ & $\mathrm{SE}=.05$ & $\mathrm{SE}=.08$ & $\mathrm{SE}=.11$ \\
\hline \multirow{2}{*}{$\begin{array}{l}\text { Road hazards } \\
\text { (\# of collisions) }\end{array}$} & $\mathrm{m}=3.2$ & $\mathrm{~m}=2.2$ & $\mathrm{~m}=1.9$ & $\mathrm{~m}=1.4$ \\
\hline & $\mathrm{SE}=.32$ & $\mathrm{SE}=.39$ & $\mathrm{SE}=.30$ & $\mathrm{SE}=.37$ \\
\hline
\end{tabular}


Table 2. Univariate statistical effects (significant effects in bold).

\begin{tabular}{|c|c|c|c|c|c|c|c|}
\hline & $\begin{array}{l}\text { inhibitory } \\
\text { control }\end{array}$ & peers & age & gender & $\begin{array}{l}\text { inh. } x \\
\text { peers }\end{array}$ & $\begin{array}{l}\text { age } x \\
\text { peers }\end{array}$ & $\begin{array}{l}\text { gender } \\
\mathrm{x} \text { peers }\end{array}$ \\
\hline \multirow{2}{*}{$\begin{array}{l}\text { SDLP } \\
\text { (meters) }\end{array}$} & $\mathrm{F}<1$ & $F=6.4$ & $\mathrm{~F}<1$ & $\mathrm{~F}<1$ & $\mathrm{~F}<1$ & $\mathrm{~F}<1$ & $\mathrm{~F}=2.5$ \\
\hline & $\mathrm{p}=.95$ & $p=.01$ & $\mathrm{p}=.96$ & $\mathrm{p}=.34$ & $\mathrm{p}=.34$ & $\mathrm{p}=.76$ & $\mathrm{p}=.12$ \\
\hline \multirow{2}{*}{$\begin{array}{c}\text { Speeding } \\
\text { (\% of distance) }\end{array}$} & $\mathrm{F}<1$ & $\mathrm{~F}<1$ & $F=5.0$ & $F=4.5$ & $F=4.2$ & $\mathrm{~F}=2.4$ & $\mathrm{~F}<1$ \\
\hline & $\mathrm{p}=.49$ & $\mathrm{p}=.49$ & $p=.03$ & $p=.04$ & $p=.046$ & $\mathrm{p}=.13$ & $\mathrm{p}=.90$ \\
\hline \multirow{2}{*}{$\begin{array}{l}\text { Red light running } \\
\text { (\# of times) }\end{array}$} & $\mathrm{F}<1$ & $F=4.4$ & $\mathrm{~F}<1$ & $\mathrm{~F}<1$ & $\mathrm{~F}<1$ & $\mathrm{~F}<1$ & $\mathrm{~F}<1$ \\
\hline & $\mathrm{p}=.34$ & $p=.04$ & $\mathrm{p}=.99$ & $\mathrm{p}=.78$ & $\mathrm{p}=.39$ & $\mathrm{p}=.44$ & $\mathrm{p}=.88$ \\
\hline \multirow{2}{*}{$\begin{array}{l}\text { Road hazards } \\
\text { (\# of collisions) }\end{array}$} & $\mathrm{F}<1$ & $F=14.4$ & $\mathrm{~F}=3.0$ & $\mathrm{~F}<1$ & $\mathrm{~F}<1$ & $\mathrm{~F}<1$ & $\mathrm{~F}=2.6$ \\
\hline & $\mathrm{p}=.74$ & $\mathbf{p}<.0005$ & $\mathrm{p}=.09$ & $\mathrm{p}=.72$ & $\mathrm{p}=.996$ & $\mathrm{p}=.38$ & $\mathrm{p}=.11$ \\
\hline
\end{tabular}

\section{DISCUSSION}

Our results show that peer passenger presence influences the behavior of young novice drivers. Interestingly, this influence can either be negative ('risk increasing') or positive ('protective'), depending on the specific driving measure. As for risk increasing effects, in line with previous studies, more red light running was established (Chein et al., 2010; Gardner \& Steinberg, 2005) and the occurrence of speeding increased when accompanied by a peer passenger (SimonsMorton et al., 2005), although the latter was only the case for a subgroup of drivers, as discussed below. The prevailing explanation for these risk increasing effects of peer presence is that young drivers are more sensitive to the pressure from risk-loving friends (Monahan, Steinberg \& Cauffman, 2009). Heightened reward sensitivity in adolescents can partly explain the sensitivity to peer pressure and the increase of risky driving with peer passengers (Chein et al., 2010). With a monetary reward a comparable increase was found for driving measures of speeding and red light running (Jongen et al., 2011). Risk increasing reward effects thus seem to occur for typical driving violations. These are characterized by a large motivational component and reflect conscious deviations from rules and safe practices (Reason, 1990). As supported by the decrease in violations in the ride without peers, young novice drivers are able to drive in a safer manner, but when peers are present they fail to do so.

As for the protective peer passenger effects, SDLP and collisions with road hazards decreased in the presence of a peer. Although speculative, the "protective" effect on SDLP might be due to an increased cognitive workload resulting from the conversation between the driver and passenger (Heck \& Carlos, 2008; Lee, 2007). An increase in cognitive workload can lead to a decrease in lateral variation (Engström, Johansson, \& Östlund, 2005). As for the protective effect on the number of collisions with road hazards, possibly peers monitored the road and served as additional 'risk detectors' thereby improving the driver's ability to detect and respond to road hazards. Similar positive effects were shown for a passenger conversation when compared with a hands-free phone conversation as passengers made references to traffic conditions, adjusted their conversation based on driving difficulty, and helped the driver navigate and identify hazards on the roadway (Strayer \& Drews, 2007). To summarize, the effect of peer passengers on driving performance was mixed. In fact, others have concluded that the effect of peer passengers among young drivers is ambiguous (i.e. in some cases positive and some negative) merely by comparing 
the results of different studies (Engström et al., 2003; Williams et al., 2007). Here we have shown that results are mixed, depending on the specific driving measure under investigation. Inhibitory control was a moderating factor of the effect peer passengers had on speeding. More specifically, in a sub-group with low inhibitory control an increase in speeding occurred with versus without peer passengers, while in a sub-group with high inhibitory control there was no effect of peer passengers on speeding. This suggests that within a socio-emotional context, those adolescents with higher inhibitory control are more successful in resisting peer pressure effects. This is highly relevant as it is known that risk taking behavior of adolescents occurs especially in situations of high emotional arousal. Interestingly in light of the current findings, cognitive control can be trained, leading to improvements in driving performance (Cassavaugh \& Kramer, 2009). A training of inhibitory control for a sub-group of young novice drivers therefore might positively affect their ability to resist peer influences and thereby lead to safer driving behavior. It cannot be ignored however that only speeding was affected by individual differences in inhibitory control. Therefore, to further reduce the problem of peer passengers in young novice drivers, such a training should be part of a broader program that teaches young drivers strategies of how to resist peer influences, and could be combined with an initiative such as GDL, requiring drivers to wait in driving together with peers (Fell, Todd \& Voas, 2011). In general these results indicate that pinpointing the underlying mechanisms of risky driving behavior is necessary to reveal the specific targets of future driver training programs aimed at safer driving and the decrease of fatalities.

\section{ACKNOWLEDGEMENTS}

We would like to thank Ron Hellenbrand and Dirk Roox for technical assistance and Brecht Janssens for his help in data collection.

\section{REFERENCES}

Cassavaugh, N. D., \& Kramer, A. F. (2009). Transfer of computer-based training to simulated driving in older adults. Applied Ergonomics, 40, 943-952.

Chein, J., Albert, D., O’Brien, L., Uckert, K., \& Steinberg, L. (2011). Peers increase adolescent risk taking by enhancing activity in the brain's reward circuitry. Developmental Science, 14, F1-F10.

Crone, E. A., \& Dahl, R. E. (2012). Understanding adolescence as a period of social-affective engagement and goal flexibility. Nature Reviews Neuroscience, 13, 636-50.

Engström, I., Gregersen, N.P., Granström, K., \& Nyberg, A. (2008). Young drivers - Reduced crash risk with passengers in the vehicle. Accident Analysis and Prevention, 40, 341-348.

Engström, J., Johansson, E., and Ostlund, J. (2005). Effects of visual and cognitive load in real and simulated motorway driving, Transportation Research Part F, 8, 97-120.

Fell, J.C., Todd, M. \& Voas, R.B. (2011). A national evaluation of the nighttime and passenger restriction components of graduated driver licensing. Journal of Safety Research, 42, 283290.

Figner, B., Mackinlay, R. J., Wilkening, F., \& Weber, E. U. (2009). Affective and deliberative processes in risky choice: Age differences in risk taking in the Columbia Card Task. Journal of Experimental Psychology: Learning, Memory and Cognition, 35, 709-730. 
Fillmore, M. T., Blackburn, J. S., \& Harrison, E. L. R. (2008). Acute disinhibiting effects of alcohol as a factor in risky driving behavior. Drug and Alcohol Dependence, 95, 97-106.

Gardner, M., \& Steinberg, L. (2005). Peer influence on risk taking, risk preference, and risky decision making in adolescence and adulthood: an experimental study. Developmental Psychology, 41, 625-635.

Heck, K.E., \& Carlos, R.M. (2008). Passenger distractions among adolescent drivers. Journal of Safety Research, 39, 437-443.

Huizinga, M., Dolan, C. V., \& van der Molen, M. W. (2006). Age-related change in executive function: Developmental trends and a latent variable analysis. Neuropsychologia, 44, 20172036.

Jongen, E. M.M., Brijs, K., Komlos, M., Brijs, T., \& Wets, G. (2011). Inhibitory control and reward predict risky driving in adolescents - a simulator study. 6th International Driving Symposium on Human Factors in Driver Assessment, Training and Vehicle Design (pp. 539546).

Lee, J.D. (2007). Technology and teen drivers. Journal of Safety Research, 38, 203-213.

Monahan, K.C., Steinberg, L. \& Cauffman, E. (2009). Affiliation with antisocial peers, susceptibility to peer influence and antisocial behavior during the transition to adulthood. Developmental Psychology, 45, 1520-1530.

Ouimet, M.C., Simons-Morton, B.G., Zador, P.L., Lerner, N.D., et al. (2010). Using the U.S. National Household Travel Survey to estimate the impact of passenger characteristics on young drivers' relative risk of fatal crash involvement. Accident Analysis \& Prevention, 42, 689-694.

Reason, J.T. (1990). Human error. Cambridge: Cambridge University Press.

Simons-Morton, B., Lerner, N. \& Singer, J. (2005). The observed effects of teenage passengers on the risky driving behavior of teenage drivers. Accident Analysis \& Prevention, 37, 973982.

Simons-Morton, B.G., Ouimet, M.C., Zhang, Z., Klauer, S.E., et al. (2011). The effect of passengers and risk-taking friends on risky driving and crashes/near crashes among novice teenagers. Journal of Adolescent Health, 49, 587-593.

Strayer, D.L. \& Drews, F.A. (2007). Cell-phone-induced driver distraction. Current Directions in Psychological Science, 16, 128-131.

Verbruggen, F., \& Logan, G. D. (2008). Response inhibition in the stop-signal paradigm, Trends in Cognitive Sciences, 12, 418-424.

Williams, A. F., \& Shabanovab, V. I. (2003). Responsibility of drivers, by age and gender, for motor-vehicle crash deaths, Journal of Safety Research, 34.

Williams, A.F., Ferguson, S.A. \& McCartt, A.T. (2007). Passenger effects on teenage driving and opportunities for reducing the risks of such travel, Journal of Safety Research, 38, 381390.

Yurgelun-Todd, D. (2007). Emotional and cognitive changes during adolescence. Current Opinion in Neurobiology, 17, 251-257. 